\title{
Formação e prática comunitária do psicólogo no âmbito do "terceiro setor"
}

\author{
Ilana Lemos de Paiva \\ Oswaldo Hajime Yamamoto \\ Universidade Federal do Rio Grande do Norte
}

\begin{abstract}
Resumo
O objetivo deste estudo é investigar a prática social do psicólogo no âmbito do "terceiro setor", buscando as estratégias utilizadas no enfrentamento das mazelas da questão social, bem como a formação necessária para atuar no campo. Foram realizadas vinte entrevistas semi-estruturadas com psicólogos que atuam em no "terceiro setor". As entrevistas foram analisadas qualitativamente, à luz da perspectiva crítica, além dos preceitos da Psicologia Comunitária e da Intervenção Psicossocial. A perspectiva defendida neste estudo é que os psicólogos devem intervir profissionalmente de forma proativa buscando o desenvolvimento, a organização e a emancipação das pessoas, grupos e comunidades, promovendo mudanças efetivas nas suas vidas.
\end{abstract}

Palavras-chave: Psicologia Comunitária; Intervenção Psicossocial; "terceiro setor”; compromisso social; emancipação humana.

\begin{abstract}
Psychologist's community training and practice at the "third sector". The purpose of this study is to investigate the social practice of psychologists working at the "third sector", focusing the strategies used to face the wounds of social issues and the professional training required for this practice. Semi-structured interviews were conducted with twenty psychologists working at the "third sector". The interviews were analyzed in a qualitative way using a critical perspective derived from community psychology and psychosocial intervention. We suggest that psychologists should work proactively pursuing the people's, group's and communities' development, organization and emancipation in order to promote real changes in their lives.
\end{abstract}

Keywords: community psychology; psychosocial intervention; "third sector"; social commitment; human emancipation.

$\mathrm{F}$ alar sobre as mazelas da questão social no Brasil não se trata de nenhuma novidade, tendo em vista que habitamos um dos países mais desiguais do planeta.

Evidentemente, a Psicologia não poderia fechar os olhos para os problemas sociais, já que somos profissionais inseridos no campo do bem-estar. Mas, de que forma podemos lidar com esse complexo fenômeno? Tais reflexões se fazem necessárias e urgentes para nossa prática social, afinal, é para a atuação neste cenário que estamos formando nossos profissionais de Psicologia.

Fenômenos como pobreza e desigualdade social têm sido tratados de formas distintas: ou não encaramos o problema de frente, ou o olhamos de forma equivocada ou insuficiente para compreendê-lo e enfrentá-lo.

A realidade a nossa volta cria, então, inimigos invisiveis, que assim se tornam porque não conseguimos (ou não queremos) enxergá-los. Percebemos isso claramente nos discursos dos profissionais que lidam com comunidades e sentem-se impotentes diante dos problemas que enfrentam.

Dessa forma, é preciso ir além de uma concepção simplista de inclusão social e perceber que "a sociedade exclui para incluir e esta transmutação é condição da ordem social e desigual, o que implica o caráter ilusório da inclusão" (Sawaia, 1999, p.8).

Concorda-se com Sawaia (1999) quando diz que em lugar de exclusão, o que temos é a dialética exclusão/inclusão, pois fazem parte do mesmo processo. E é justamente essa lógica dialética que compreende a exclusão social como parte sine qua non do sistema, o que leva à total negação das concepções de adaptação e normatização, ou mesmo da culpabilização individual relacionada à pobreza. Ainda segundo Sawaia (1999): "o pobre é constantemente incluído, por mediações de diferentes ordens, no nós que o exclui, gerando o sentimento de culpa individual pela exclusão" (p. 9), e conclui que a exclusão

é processo que envolve o homem por inteiro e suas relações com os outros. Não tem uma única forma e não é uma falha do sistema, devendo ser combatida como algo que perturba a 
ordem social, ao contrário, ele é produto do funcionamento do sistema. (Sawaia, 1999, p. 9, itálicos nossos)

Mesmo diante do quadro de miséria e violência que vivenciamos no país, as perspectivas atuais apontam para a redução do gasto público destinado às políticas sociais.

Com o enxugamento do Estado, o chamado "terceiro setor" tem sido utilizado como estratégia política de enfrentamento às mazelas da questão social, e tem se configurado como amplo campo de atuação para o psicólogo.

Dentro da perspectiva adotada por este estudo, a Psicologia, e o "terceiro setor" em geral, precisam compreender que o excluído não está à margem da sociedade, mas ele repõe e sustenta a ordem social, gerando sofrimento na lógica da inclusão perversa presente no sistema social vigente, como afirmamos anteriormente. Sendo assim, a preocupação é que as ações sociais articuladas no âmbito do "terceiro setor" possam não considerar a relação entre a lógica econômica e a coesão social anteriores às situações de ruptura representadas pela exclusão.

Embora no nosso atual cenário político, social e econômico, existam novos elementos, novas faces, novas expressões imediatas da questão social, que poderiam levar a pensar que é nova, "ela continua a manter os traços essenciais e constitutivos da sua origem" (Pastorini, 2004, p. 12). Trata-se aqui de entender, afinal, quais são as categorias que estão superadas, quais são as demandas não integráveis à lógica capitalista. No limite, essas são questões insolúveis para o capital.

Para sair do discurso funcionalista e fatalista, precisamos vislumbrar outras possibilidades de interpretação por parte dos próprios sujeitos, para que concebam posturas críticas, que possam desencadear ações organizativas, que explicitem seus potenciais de sujeitos e de comunidade. Saindo do que Demo (2003) chamou de pobreza política, que é a negação da autonomia emancipatória. Fazendo novas construções sobre si mesmo, sobre sua comunidade, sobre seu mundo. Na nossa prática social, poderíamos dizer que, se não estimulamos a organização, a participação e a emancipação da comunidade, não devemos ter expectativas de alcançar mudanças significativas ${ }^{1}$.

Por isso, consideramos que o campo das políticas sociais configura-se como mais do que um espaço novo de atuação para o psicólogo, possuindo foco de trabalho e objetivos bem diferentes de uma prática tradicional. Esse é um espaço de atuação que se nutre de conhecimentos psicológicos diversos e uma concepção de indivíduo abordado dentro de um viés psicologista, não responde às necessidades dessa nova demanda. Nesse contexto, passamos a nos referir, então, a indivíduos concretos, vivos, historicamente constituídos.

Muitos psicólogos atuam por um ideal de mudança social, mas, muitas vezes, não sabem por onde começar. Há a clara necessidade de espaços de reflexão sobre suas atuações, além da formação contínua, para que se possam dar respostas mais efetivas às demandas sociais. Parece-nos que há uma prática irrefletida, que o cotidiano de trabalho mascara a concretude do real (Kosik, 2002), que os psicólogos se afastam dela.

Nesse sentido, o objetivo deste estudo foi investigar a formação e a prática comunitária do psicólogo, no âmbito do “terceiro setor". Dito em outras palavras, buscou-se, a partir de uma perspectiva crítica, analisar as estratégias utilizadas no enfrentamento da pobreza, bem como a formação necessária para atuar no campo.

\section{Materiais e Método}

Foram realizadas 20 entrevistas semi-estruturadas com psicólogos que atuavam em 14 (quatorze) diferentes instituições sem fins lucrativos. As entrevistas foram gravadas em áudio, sendo firmado Termo de Consentimento Livre e Esclarecido com cada um dos psicólogos.

A finalidade do roteiro de entrevista era relacionar o trabalho do psicólogo com um contexto institucional específico, conhecer quais são as suas demandas de trabalho, para, por fim, questioná-lo sobre as estratégias da Psicologia utilizadas em resposta a elas. Enfim, buscou-se, com as entrevistas, o desenho da prática social do psicólogo no âmbito do "terceiro setor" e suas problematizações.

Os dados da pesquisa foram analisados à luz da perspectiva crítica, além dos referenciais da Psicologia Comunitária (PC) e da Intervenção Psicossocial, para uma relativa comparação entre a prática dos psicólogos entrevistados e os preceitos desenvolvidos pela área.

A abordagem metodológica utilizada na análise das entrevistas está baseada no Método Comparativo Constante - MCC, caracterizado pelo fato de que, desde o começo, o pesquisador codifica e reflexiona sobre o tipo de dados que está coletando (Trinidad, Carrero \& Soriano, 2006). Nessa abordagem, a elaboração das categorias é um dos elementos centrais. Para Strauss e Corbin (1990), a categorização é o processo de agrupar conceitos que parecem pertencer ao mesmo fenômeno. Inicialmente, a comparação origina categorias desconexas, que aos poucos vão se conectando, formando o desenho que se pretendia investigar. Dessa forma, na presente pesquisa, não foi definida nenhuma categoria a priori, mas elaboradas a partir da análise, comparando-se resposta a resposta dos participantes.

Vale salientar ainda que, para a codificação e categorização dos dados, foi utilizado o software para análise qualitativa QDAMiner (Qualitative Data Analysis Software).

\section{Resultados e Discussão}

Para muitos psicólogos entrevistados, o momento da realização desta pesquisa foi um primeiro momento de reflexão sobre sua prática, sobre o que pensam e sobre a problemática que é estar inserido no "terceiro setor".

Um primeiro ponto de discussão diz respeito à formação para a intervenção psicossocial, pois a crise de identidade do psicólogo social deve-se, em parte, à formação precária que receberam para atuar junto a esses contextos.

Nesses contextos de atuação, faz-se necessário pensar, não em intervenções centradas no indivíduo, mas em intervenções psicossociais, que pensem o grupo social e sua organização. $\mathrm{Na}$ literatura psicológica brasileira, encontramos poucos trabalhos escritos sobre intervenção psicossocial, apesar da ampla inserção de psicólogos em organizações sem fins lucrativos e 
em programas governamentais de assistência social.

O objetivo da Intervenção Psicossocial é, justamente, reduzir ou prevenir situações de vulnerabilidade, melhorando condições humanas, e, para isso, requer uma abordagem interdisciplinar. Sarriera (2004) define intervenção psicossocial da seguinte maneira:

A intervenção psicossocial é, dessa maneira, um trabalho de relação direta entre facilitador-interventor com o grupo-alvo, que incide em transformações nas histórias, ou melhor, na vida cotidiana, espaço onde as histórias pessoais, grupais ou coletivas ocorrem. (p. 25)

Podemos dizer que esse tipo de intervenção, diferentemente da Psicologia individual, se sustenta na prevenção e educação, na promoção e otimização, no fortalecimento dos recursos e potencialidades dos grupos e coletivos sociais (Espinosa, 2004).

Os psicólogos entrevistados reconhecem a limitação da formação que tiveram. Quando perguntados como a graduação em Psicologia contribuiu para sua prática comunitária atual, todas as respostas apontam para alguma falha grave (Tabela 1).

Tabela 1

Contribuição da formação dos psicólogos para a prática social

\begin{tabular}{lc}
\hline \multicolumn{1}{c}{ Formação } & Casos $(N)$ \\
\hline Dissociada da prática social & 4 \\
Valorização de áreas clássicas & 7 \\
Não prepara suficientemente & 9 \\
Total & 20 \\
\hline
\end{tabular}

Um primeiro grupo de respostas indica a formação como dissociada da prática social, ou seja, afastada dos problemas e grupos sociais em situação de vulnerabilidade, como vemos nos exemplos destacados abaixo:

Eu nunca vi uma ação específica, vim ver já no final do curso, eu já estava aqui envolvida, então nem fazia sentido ir correr atrás, mas não tinha acesso às informações de ações, práticas, mesmo, que não só pesquisa, ou teoria... (E2)

Na universidade a gente não tem contato com outras experiências, que estejam acontecendo, que estão consolidadas (...). De ter conhecimento dessas práticas, de práticas da Psicologia social e comunitária que estão acontecendo hoje, a gente não teve. Acho que isso faltou, até para segurança profissional. (E8)

A Psicologia constitui-se historicamente como uma atividade a serviço da classe dominante, e a entrada em campos como o da política social força-lhe a reaprender a fazer e pensar Psicologia. O que não deve ocorrer, no entanto, é a criação de mundos paralelos (Vasconcelos, 1999), ou seja, a dissociação completa entre a formação em Psicologia e a nossa atuação, que somos obrigados a reinventar quando nos deparamos com outra realidade, diferente da que aprendemos nas salas de aula.

Outra questão importante diz respeito ao segundo grupo de respostas, que aponta também a formação precária em Psicologia Social, mas pela ênfase dos cursos em áreas tradicionais e a falta de disciplinas na área social, como disse o entrevistado 13 , "O curso ficou muito no campo da clínica. (...) e não problematizava com as questões sociais". Vejamos outro exemplo, no destaca da fala do entrevistado 3 :

Pensando de forma específica, o que eu estudei na graduação que me ajuda a estar aqui? Teoricamente, não me ocorre, não estou me lembrando de nada, fora algumas disciplinas complementares (...). Então, eu acho que existe um novo movimento do Conselho, dessa história de Psicologia e compromisso social que tem despertado, tem apontado essas novas alternativas, que é necessário trabalhar com essa população, que a Psicologia tem que sair do seu consultório, agora teoricamente, como fazer isso eu não conheço, pode ser que tenha, mas eu não conheço. (E3)

O debate a respeito dos problemas sociais não adentra a formação básica da graduação do psicólogo. Não se trata, então, de criticar o atendimento individual, mas sim a pura e simples transposição de um modelo clínico para um trabalho que requer dimensões sociais e políticas muito mais abrangentes.

Apesar de ser tema tão amplamente discutido, mas, sem dúvida, não superado, a formação maciça em clínica prepara para uma relação dual, importante, mas com aplicação pouco eficaz para a inserção na comunidade. Além disso, não é uma formação que favoreça o desenvolvimento de trabalhos interdisciplinares, nem orientada para demandas específicas que se apresentam nesse tipo de instituição. Não favorece, por exemplo, o planejamento das ações a serem desenvolvidas na comunidade (não favorece nem o contato efetivo com a comunidade), nem a avaliação dessas ações, essencial no âmbito social, como discutimos anteriormente.

Além disso, esse tipo de formação torna precário também o conhecimento e a discussão a respeito de políticas públicas, Sistema de Garantia de Direitos, Estatuto da Criança e do Adolescente, Lei Orgânica de Assistência Social (LOAS), Lei de Diretrizes e Bases (LDB), Sistema Único de Saúde (SUS), Sistema Único de Assistência Social (SUAS), entre outras, e como o psicólogo se insere nessas discussões.

Sobre isso, Botomé (1979) questionava os currículos de Psicologia, já que os mesmos não preparavam os alunos para atuar no complexo cenário das dificuldades da nossa população. Para o autor, os psicólogos se preparavam basicamente para situações de testes, salas de clínica ou laboratórios e ambientes de treinamento. O quadro atual não parece diferir de forma significativa daquele apontado pelo autor, quase três décadas atrás, o que nos leva a afirmar que ainda somos os mesmos, apesar de toda reflexão realizada dentro da Psicologia brasileira.

Esses fatores trazem como conseqüência o sentimento de insegurança e falta de preparo na atuação profissional, já que alguns psicólogos afirmam que não se sentem preparados suficientemente, como destacamos na fala seguinte:

Eu acho que na área social... eu, claro, já tive alguma experiência, eu venho caminhando nesse sentido, mas eu acho que é isso, ainda está em construção, eu ainda não me sinto preparada, sabendo o que, como é, como faz, ainda não. (E4)

A questão que se coloca é: como podemos nos capacitar adequadamente, para uma melhor atuação diante das demandas sociais? 
O Colégio Oficial de Psicólogos da Espanha (COP, 2008) publicou documentos que tratam da formação do psicólogo na área que denominam de Psicologia da Intervenção Social. Tais documentos chamam a atenção para a complexidade dessa formação, que deve se compor de um corpo comum a todos os profissionais que atuam no setor, incorporando modelos teóricos e conhecimentos da Psicologia social como área extensa, além de técnicas de avaliação e intervenção gerais, porém, aplicadas ao contexto social, em seus diferentes níveis: individual, grupal e comunitário.

No entanto, cada setor específico de intervenção social vai requerer uma aprendizagem específica que, somada à anterior, conformaria uma segunda especialidade. Fala-se, então, de conteúdos transversais (comuns a todos os setores de intervenção social) e específicos (para cada setor de intervenção), como por exemplo, atuação junto a mulheres, terceira idade, pessoas com deficiência, etc.

Logo, a formação para a intervenção psicossocial deve abarcar:

Montero (2004) também traz uma reflexão sobre características desejáveis para a formação dos psicólogos comunitários. Antecipa que esta não é uma questão simples,

Tabela 2

Aspectos fundamentais para a formação em intervenção psicossocial

1. Conhecimento do marco normativo, administrativo e organizativo dos programas e serviços sociais;

2. Características psicossociais dos setores de intervenção;

3. Estratégias e técnicas mais habituais de intervenção (nos níveis individual, grupal e comunitário);

4. Modelos teóricos de intervenção social;

5. Metodologia: planejamento, avaliação de necessidades, avaliação de programas.

já que a PC não pode se fundamentar unicamente nos aspectos teóricos da literatura existente no campo, estando apoiada na união entre prática e reflexão sobre a prática. Esse cuidado na formação deve vir acompanhado do melhor ensino teórico e metodológico possível, para uma prática rigorosa e ética. Por fim, a autora chama a atenção para a reflexão crítica que deve acompanhar a formação e a prática comunitária, pois cada intervenção exige um plano de trabalho específico. No entanto, alguns temas são essenciais, como noção de comunidade, participação, compromisso e investigação-ação.

No nosso contexto, acreditamos que o isolamento profissional e acadêmico tem resultado em formações insuficientes e desconectadas da realidade social, além de gerar angústia e insegurança para os profissionais que estão adentrando na área.

Disciplinas isoladas, sem a construção de um corpo conceitual consistente, nem de metodologias adequadas a novas demandas, tem sido a característica da Psicologia aplicada a comunidades nas nossas Universidades e Faculdades. Além do mais, o conhecimento sobre políticas públicas, aliado à capacidade de reflexão crítica, são, a nosso ver, essenciais para a formação do psicólogo.

Questionamos aos psicólogos, também, quais eram os objetivos do seu trabalho na instituição e obtivemos respostas bastante variadas (Tabela 3 ):

Tabela 3

Objetivos da prática profissional do psicólogo no "terceiro setor"

\begin{tabular}{lc}
\hline \multicolumn{1}{c}{ Objetivos } & Casos $(N)$ \\
\hline Proporcionar bem-estar e qualidade de vida & 3 \\
Defesa de direitos & 1 \\
Colaborar com políticas públicas & 1 \\
Contribuir para o desenvolvimento pessoal & 4 \\
Apoio emocional & 1 \\
Contribuir com a instituição & 3 \\
Aumento da participação cidadã & 1 \\
Melhorar qualidade da educação & 1 \\
Compreender aspectos psicológicos envolvidos na pobreza & 1 \\
Não respondeu & 4 \\
Total & 20 \\
\hline
\end{tabular}

Acerca da PC, o poder e o controle sobre as circunstâncias da vida, por parte dos membros da comunidade, bem como a transformação social, são objetos deste campo da Psicologia (Montero, 2004). Nesse sentido, objetivos citados por poucos psicólogos estão condizentes com seus preceitos, como melhorar a participação cidadã, defesa de direitos, contribuir com políticas públicas etc., como mostra a fala do entrevistado 13:

Eu acho que o trabalho que eu tenho feito, sobretudo, é tentar fazer com que as pessoas possam exercer a sua cidadania ativa em todas as esferas da vida. (...) que elas possam participar, que elas possam ser pessoas autônomas, que elas possam construir a sua, ser protagonistas mesmo de suas histórias e daquilo que elas pensam que pode ser feito para melhorar as condições de vida delas.

No entanto, há indicação de que a atuação do psicólogo, em sua maioria, tem se limitado a mudanças num âmbito individual, ou até mesmo institucional. As mudanças na vida dos sujeitos são atribuídas a alguém externo à comunidade, a um fazer técnico, não favorecendo o protagonismo de seus personagens.

Nas demais respostas dos psicólogos, percebemos que o bem-estar, a qualidade de vida, a mudança, se concentram em cada pessoa que faz parte do programa ou projeto social, é a sua finalidade última. Além disso, é responsabilidade da equipe realizá-la. Diferentemente do exemplo anterior, os objetos da intervenção não são a participação e organização social.

Os psicólogos precisariam, então, pensar uma nova concepção de prática profissional, voltada para a construção de sujeitos com "capacidade de ação e proposição" (Dimenstein, 2001, p. 62). Na verdade, como já assinalamos, o psicólogo ainda não está seguro do que pode fazer diante do quadro de pobreza no qual começa a atuar.

Difícil, então, encontrar o que é objetivo da atuação do psicólogo nesse contexto, se partirmos de concepções individualizantes e universalizantes. O exemplo destacado abaixo ilustra esse viés da Psicologia:

A partir do momento que a direção contrata um psicólogo pra 
trabalhar nesse programa, é porque começa a perceber que existem outros aspectos, não só biológico-sociais na questão da desnutrição. Então, quando a gente encontra uma família desnutrida, a gente vai avaliar, realmente existem aspectos psicológicos, a relação mãe-bebê que ficou, seja mais dificultosa, a criança não consegue absorver os nutrientes da alimentação. O nosso trabalho é de tentar proporcionar um debate acerca das principais repressões... (E8)

Parece-nos que há uma tentativa de justificar a presença de um psicólogo em uma equipe que trabalha em contextos de pobreza. No entanto, as justificativas se voltam para a psicologização dos problemas sociais que as pessoas enfrentam. Na fala acima, por exemplo, a criança está desnutrida pela relação mãe-bebê estabelecida. Assim, o psicólogo está num terreno seguro, isso sim, ele aprendeu a lidar na formação.

Dimenstein (2000) fala-nos da nossa cultura profissional, que ainda é permeada pelo ideário individualista, pelo psicologismo ou cultura psicanalítica. Para a autora, tal cultura levar-nosia a agir sobre a realidade, como se as pessoas, dos diversos grupos sociais, tivessem a mesma visão de mundo e modelos de subjetividade que fundamentam suas formas de atuação.

Tal como em outras áreas que se abriram para a Psicologia, falta também ao psicólogo que começa a atuar na assistência social uma reflexão aprofundada sobre o contexto em que se dá essa atuação, bem como a clareza acerca da dimensão política e filosófica que envolve a intervenção social.

Outra questão pesquisada refere-se às ferramentas teóricas e metodológicas utilizadas pelos psicólogos no trabalho do "terceiro setor". Como os psicólogos efetivamente respondem às demandas sociais? Em que perspectiva teórica embasam suas ações? Que atividades desenvolvem? Que instrumentos e técnicas utilizam?

Sobre a rotina de trabalho, as atividades que realizam no cotidiano de trabalho (Tabela 4), os entrevistados apontaram o seguinte:

Tabela 4

Rotina de trabalho do psicólogo no "terceiro setor"

\begin{tabular}{lc}
\hline \multicolumn{1}{c}{ Rotina } & Casos $(N)$ \\
\hline Atendimento clínico individual & 7 \\
Execução de projetos & 6 \\
Atendimento a jovens e suas famílias & 1 \\
Levantamento de demandas & 1 \\
Planejamento institucional & 1 \\
Grupos terapêuticos & 2 \\
Gestão organizacional & 2 \\
Total & 20 \\
\hline
\end{tabular}

Evidentemente, ao analisar as entrevistas, devemos levar em consideração as missões diferenciadas que apresentam cada uma das instituições pesquisadas. Dessa forma, as atividades dos psicólogos estão diretamente relacionadas com a natureza da instituição, bem como com as demandas que se apresentam em cada campo de atuação. Entretanto, sobre a rotina de trabalho, é possível perceber um dado interessante. Embora muitos afirmem que, em seu cotidiano profissional, realizam predominantemente atendimentos clínicos, e outros que atuam como psicólogos organizacionais (realizando recrutamento e seleção, etc.), é interessante notar que alguns psicólogos definem suas atividades atreladas à execução de projetos. Nesses casos, a rotina é variada e foge ao que é entendido como trabalho de psicólogo.

Para isso, é necessário um perfil dinâmico, com atuação multidisciplinar, com conhecimentos na área de elaboração de projetos, captação de recursos, educação social, etc..

Já discutimos neste trabalho sobre o que fazem os psicólogos na intervenção psicossocial, e o quanto nossa formação não contribui para o perfil de profissional necessário no campo. Mas, no cotidiano de trabalho, os papéis a desempenhar estão claros? Assumir múltiplas funções, como afirma o exemplo acima, faz parte do seu papel de interventor social? O papel do psicólogo no contexto social deve ser bem definido, como em qualquer outra área de atuação. Evidente que bem definido não quer dizer estático ou inflexível.

Para Sanchéz Vidal (2007), o papel do psicólogo é o coração da intervenção psicossocial, devendo estar sempre aliado à ética, à participação e à multidisciplinaridade. Para o autor, o papel a desempenhar define-se como uma constelação de funções integradas que o psicólogo assume em resposta às exigências ou demandas repetidas advindas dos coletivos e das situações que enfrenta na sua prática cotidiana.

Enfim, na medida em que as demandas apresentadas sejam similares (reclamem quase sempre o mesmo tipo de função), ou diferenciadas (reclamem funções diversas), o papel será mais homogêneo - contando com poucos elementos funcionais, ou heterogêneo - tendo componentes mais variados e difíceis de integrar na prática.

Diante da diversidade de funções, poderíamos considerar que há um denominador comum acerca do papel do psicólogo no contexto da intervenção social? Montero (2004) indica que o exercício dessa Psicologia deve atender a, pelo menos, quatro grandes áreas:

1) Prevenção, especialmente primária, com promoção de condutas consideradas desejáveis; 2) Intervenção, muitas vezes ligada à investigação com sentido participativo; 3) Investigação; 4) Avaliação.

O papel da investigação é essencial na prática social, e não está presente nas respostas dos psicólogos. Ainda segundo Montero (2004), um marco dentro deste campo da Psicologia é, justamente, buscar a compreensão dos fenômenos estudados, aprender a partir dos fenômenos com os quais se intervém, para que se possa sistematizar a ação e avaliá-la, conforme discussões anteriores.

Por fim, nunca é demais lembrar, que o papel do psicólogo no contexto social difere na essência do papel clínico tradicional. $\mathrm{O}$ atendimento clínico, nos moldes tradicionais, nesses contextos de atuação, nos parece um equívoco por parte dos psicólogos.

O papel na intervenção social, quando bem compreendido e executado, pode ser considerado o núcleo da identidade social do psicólogo (Sanchéz Vidal, 2007), a qual tem sido buscada pelos profissionais entrevistados sem muito êxito. A função assumida e a identidade, então, estariam inter-relacionadas.

Sobre a função da prática social do psicólogo, Martin-Baró (1996) define como fundamental a desalienação das pessoas e grupos, eliminando mecanismos que bloqueiam a consciência da identidade social. E essa função está ligada ao verdadeiro 
compromisso social do psicólogo, de caráter histórico.

Dessa forma, concorda-se com o autor quando diz que o que importa é saber para onde vai o "quefazer psicológico" (MartinBaró, 1996, p. 13), que efeito objetivo a atividade psicológica produz em uma determinada sociedade.

A resposta que o autor aponta é justamente refletir criticamente sobre quais as consequências históricas concretas que nossas atividades estão produzindo, sejam quais forem. No nosso entendimento, no entanto, a escolha de determinadas abordagens e técnicas psicológicas para a intervenção psicossocial já traria, por si só, algumas consequências.

Sobre isso, é interessante notar que, mesmo para aqueles psicólogos que afirmaram que seu papel dentro da instituição não se limita ao tradicional em Psicologia, a escolha da abordagem, geralmente, relaciona-se com a Psicologia clínica (Tabela 5).

Tabela 5

Abordagens e técnicas psicológicas utilizadas no trabalho em instituições do "terceiro setor"

\begin{tabular}{lc}
\hline \multicolumn{1}{c}{ Abordagens e técnicas } & Casos $(N)$ \\
\hline Abordagem multidisciplinar & 3 \\
Psicologia Social/Comunitária & 2 \\
Gestalt-Terapia & 4 \\
Abordagem corporal & 1 \\
Clínica e social & 1 \\
Não tem clareza de abordagem & 6 \\
Psicanálise & 1 \\
Não respondeu & 2 \\
Total & 20 \\
\hline
\end{tabular}

Com algumas exceções, há indicativos de que tais abordagens são as únicas possíveis ou acessíveis aos entrevistados.

Dentre aqueles que não conseguem ter clareza do corpo teórico-conceitual que sustenta o seu trabalho, há a tentativa de mesclar as diversas abordagens da área clínica, na busca (ilusória) de, assim, dar conta da complexidade que envolve o trabalho social.

Vejamos o exemplo do entrevistado 1, em que consideramos que a sustentação teórica não está clara para o profissional:

Pois é, eu me formei com base analítica, mas a técnica analítica eu não sou muito adepta não, gosto muito da área fenomenológica. Essa coisa humanística também... Eu vou mais por esse lado, lógico, a gente tem que ter uma visão geral e a análise, a teoria analítica te dá um fundamento. Mas, eu me percebo fazendo um trabalho corporal... Eu estou muito tentando seguir um caminho, ainda não defini, estou descobrindo aos poucos.

É claro que não estamos querendo dizer com isso que o psicólogo deve realizar sua prática social fechado em uma abordagem teórica específica. Até porque, como já discutimos, faz-se necessário conhecer a realidade primeiro, para atuar nela a posteriori.

Em primeiro lugar, o problema não está num suposto pluralismo teórico-metodológico, mas na coerência com o objeto de intervenção em questão, ou seja, com as demandas sociais. Ademais, outro fator de reflexão é se tal mesclagem irrefletida acerca de teorias e métodos não traz incoerência do ponto de vista epistemológico. Além disso, se partirmos de vários olhares, como foi afirmado, que visão de homem e de sociedade teremos?

Pensando a relação dialética entre teoria e prática, necessitamos de um corpo teórico-conceitual consistente e coerente, que fundamente e guie nossas ações. Afinal, da mesma forma que a instituição precisa ter clara a sua proposta políticopedagógica, é importante que o psicólogo também saiba de que lugar parte e aonde quer chegar.

Para a construção de novos referenciais de atuação, é preciso lembrar que a união entre teoria e prática é um dos princípios fundamentais da Psicologia Comunitária. É a consideração do caráter ativo dos participantes provenientes das comunidades, bem como a redefinição do papel dos psicólogos comunitários, que pode contribuir com o desenvolvimento da perspectiva metodológica participativa que caracteriza o método em psicologia comunitária (Montero, 2004).

As abordagens tradicionais da Psicologia clínica, que pensam o indivíduo isolado de seu contexto social, certamente não nos ajudarão muito, por motivos amplamente citados. Apenas dois psicólogos abordam a Psicologia social ou comunitária como fazendo parte de seu embasamento teórico, o que causa preocupação.

De fato, há indícios, nas falas dos psicólogos, de que a Psicologia fora dos âmbitos da clínica não nos identifica como verdadeiramente psicólogos. É preciso romper com essa cultura profissional e buscar referenciais teórico-metodológicos que respondam às demandas por mudança social.

Montero (2004) relata como as preocupações com a questão social estavam completamente fora do âmbito da Psicologia, antes do advento da Psicologia comunitária:

Mi experiencia personal fue la de encontrarme, a mediados de los años setenta, ante problemas sociales que no podían ser ni estudiados ni resueltos mediante la aplicación de las formas usuales de tratamiento desarrolladas hasta el momento por la psicología. (p. 81)

A Psicologia certamente mudou desde então, mas não mudaram, suficientemente, os profissionais psicólogos que a fazem, seja no âmbito técnico ou acadêmico. Defende-se aqui, inclusive, o resgate de influências teóricas que demarcaram o campo da PC, como Marx, Gramsci, Paulo Freire, Martin-Baró, Fals Borda etc., aliado a novas contribuições dentro do campo da Psicologia e de outras áreas de conhecimento. E que técnicas utilizar? O que conhecemos além da aplicação de testes e a prática da psicoterapia?

Para Montero (2004), podemos lançar mão de um pluralismo metodológico que atenda às novas demandas, não se descartando o uso de formas tradicionais de investigação e intervenção social, como a aplicação de entrevistas e pesquisas, observação, técnicas de dinâmicas de grupos, avaliações psicológicas, etc.

Entretanto, tanto os métodos tradicionais quanto os participativos, devem estar orientados pelos princípios e valores de uma Psicologia voltada para a comunidade, encontrando adaptações de caráter participativo a elas.

Nossa prática, então, não deve estar pautada por um conjunto de técnicas que esvaziam os objetivos da transformação social. Como dissemos anteriormente, é preciso pensar, também, se as 
atividades que realizamos de certa forma dificultam a perspectiva de emancipação, ao invés de promovê-la. Os critérios apontados acima podem nos ajudar na escolha de tais técnicas.

$\mathrm{Na}$ verdade, como qualquer área que se abre para a atuação profissional da Psicologia, é preciso uma avaliação dos seus saberes e fazeres, de modo a que se possa falar em um efetivo compromisso social da profissão. Nesse sentido, os psicólogos problematizam o fato de estarem inseridos em campo tão amplo e complexo, que exige trabalho interdisciplinar, pois, como disse a entrevistada 2: "não estamos ali para trabalharmos sozinhas".

De fato, como aponta Martínez (2003), quando o objetivo é promover os sujeitos em protagonistas de sua própria mudança, nenhum trabalhador social por si só, possui as ferramentas necessárias para poder desenvolver a tarefa adequadamente. Até porque, na equipe interdisciplinar, as distintas visões e perspectivas de cada profissional diante dos problemas sociais, são complementares:

Concebimos, por tanto, el abordaje del problema psicosocial como un abordaje de equipo entre los profesionales implicados y el grupo de población (afectados y no afectados) referente. Entre los profesionales deberá existir una coordinación de acciones y la consiguiente subordinación entre las mismas de acuerdo con una estrategia común. (Martínez, 2003, p. 17)

Afinal, que condições seriam necessárias para o profissional que vai atuar em contextos de pobreza e desigualdade? Poderíamos pensar num perfil específico? Montero (2004) discutiu características que considera importantes para o perfil de um psicólogo comunitário, como por exemplo: sensibilidade social e sentido de justiça social; aceitação da diversidade do Outro; estar sempre aberto para a aprendizagem, não desprezando o conhecimento advindo de lugares, pessoas e situações que estão fora dos centros de saber; pôr o seu conhecimento a serviço das transformações necessárias e desejadas pelas pessoas com as quais se vai trabalhar; e, em última instância, não tentar exercer a PC se não está disposto a atuar de acordo com os valores de respeito ao Outro, ou com as condições anteriores.

Acreditamos que as características apontadas são importantes ao pensarmos a prática social do psicólogo. De fato, é de extrema relevância conhecer e refletir a realidade social na qual iremos atuar. E para que nosso compromisso social seja efetivo, é preciso pensar sobre como está se dando a nossa inserção no "terceiro setor".

Certamente, poderemos ampliar nossos limites de atuação repensando nossas ferramentas teórico-metodológicas. Não está na hora de revermos os modelos de intervenção adotados? Conhecemos a comunidade, sabemos das suas necessidades? Podemos oferecer projetos sociais mais amplos que vislumbrem mudança social? Sem uma reflexão acerca da formação e dos modelos e instrumentos adotados, e fundamentalmente da ética que deve permear nossa atuação, não poderemos falar, efetivamente, em compromisso social da Psicologia.

\section{Considerações Finais}

Teria ela própria que cegar também para com-
preender que uma pessoa se habitua a tudo, sobretudo se já deixou de ser pessoa (José Saramago, em Ensaio sobre a cegueira).

Não há compromisso social da Psicologia se esta não estiver envolvida com um projeto amplo de mudança social, que busque as causas e não a superfície do problema, ou medidas paliativas de conformação com sua condição atual.

Acreditamos que apenas uma prática aliada à reflexão, pode levar a uma atuação comprometida. Os limites do nosso compromisso profissional e de nossa atuação estarão relacionados com nossa capacidade de compreender. Até onde nossos olhos conseguem enxergar?

Esse é o dilema do psicólogo social: a expectativa de mudança esbarra nos limites da própria atuação inserida nos marcos do capitalismo.

No entanto, não é o psicólogo quem vai mudar o mundo, mas, evidentemente, uma ação comprometida, contextualizada, política, articulada, que vise à emancipação dos sujeitos, poderá iniciar alguma transformação.

Quando chamamos os psicólogos para olharem a realidade como ela é, não pretendemos que assumam uma postura fatalista, pois concordamos com Martin-Baró (1996) que o fatalismo é um tipo de barreira à mudança. O conformismo social não é nada mais que a interiorização das relações de dominação. Assumir que nada se pode fazer diante dos problemas sociais é naturalizar as circunstâncias atuais, desconsiderando seu caráter histórico.

\section{Referências}

Botomé, S. (1979). A quem nós, psicólogos, servimos de fato? Psicologia, 5(1), $1-15$.

Colegio Oficial de Psicólogos de Espanã (COPE) (2008). Perfiles profesionales del psicológo. Madrid: Colegio Oficial de Psicólogos de Espanã.

Demo, P. (2003). A pobreza da pobreza. Petrópolis: Vozes.

Dimenstein, M. (2000). A cultura profissional do psicólogo e o ideário individualista: implicações para a prática no campo da assistência pública à saúde. Estudos de Psicologia, 5(1), 95-121.

Dimenstein, M. (2001). O psicólogo e o compromisso social no contexto da saúde coletiva. Psicologia em estudo, 6(2), 57-63.

Espinosa, L. M. C. (2004). Psicología Comunitaria de la Salud. In: G. M. Ochoa, J. H. Olaizola, L. M. C. Espinosa, \& M. M. Martínez (Orgs.), Introducción a la psicología comunitaria (pp. 17-41). Barcelona: Editorial UOC.

Kosik, K. (2002). Dialética do concreto. Rio de Janeiro: Paz e Terra.

Martín-Baró, I. (1996). O papel do psicólogo. Estudos de Psicologia, 2(1), 7-27.

Martínez, A. (2003). Psicologia e compromisso social: desafios para a formação do psicólogo. In A. M. Bock (Org.), Psicologia e compromisso social (pp. 143-160). São Paulo: Cortez.

Montero, M. (2004). Introducción a la psicología comunitária: desarrollo, conceptos y procesos. Buenos Aires: Paidós.

Pastorini, A. (2004). A categoria “Questão Social” em debate. São Paulo: Cortez.

Sanchéz Vidal, A. (2007). Manual de Psicología Comunitária: un enfoque integrado. Madrid: Ediciones Pirámide.

Sarriera, J. C. (2004). Psicologia comunitária: estudos atuais. Porto Alegre: Sulina.

Sawaia, B. (1999). Exclusão ou inclusão perversa? In B. Sawaia (Org.), As artimanhas da exclusão: análise psicossocial e ética da desigualdade social 
(pp. 7-13). Petrópolis: Vozes.

Strauss, A., \& Corbin, J. (1990). Basics of qualitative research: Grounded Theory procedures and techniques. London: Sage Publications.

Trinidad, A., Carrero, V., \& Soriano, R. (2006). Teoría Fundamentada "Grounded

Theory”: la construcción de la teoría a través del análisis interpretacional.
Madrid: Centro de investigaciones sociológicas.

Vasconcelos, E. M. (1999). Mundos paralelos, até quando? Os psicólogos e o campo da saúde mental pública no Brasil nas últimas duas décadas. In A. M. Jacó-Vilela, F. Jabur, \& H. B. C. Rodrigues (Orgs.), Clio-Psyquê, Histórias da Psicologia no Brasil (pp. 121-147). Rio de Janeiro: UERJ/NAPE.

1. É importante ressaltar que a categoria da emancipação humana é abordada aqui, a partir da perspectiva crítica, pensando que, em um projeto emancipatório da sociedade, é preciso romper a relação entre a subordinação, a discriminação e a subalternidade, para a efetivação de políticas que contribuam com o processo democrático. Mas, para isso, requer-se ação e sujeitos políticos, emancipados, capazes de romper com a situação de submissão em que vivem (Pastorini, 2004).

Ilana Lemos de Paiva, doutora em Psicologia Social pela Universidade Federal da Paraíba/Universidade Federal do Rio Grande do Norte, é professora adjunta da Universidade Federal do Rio Grande do Norte. Oswaldo Hajime Yamamoto, doutor em Educação pela Universidade de São Paulo, é professor titular na Universidade Federal do Rio Grande do Norte. E-mail: oswaldo.yamamoto@gmail.com 